\title{
Stem cell targeted therapeutic approaches for molecular subtypes of clinical breast cancer (Review)
}

\author{
NITIN TELANG \\ Cancer Prevention Research Program, Palindrome Liaisons Consultants, Montvale, NJ 07645-1559, USA
}

Received October 24, 2018; Accepted November 29, 2018

DOI: $10.3892 /$ wasj.2018.3

\begin{abstract}
The global profiling of differentially expressed genes in subtypes of clinical breast cancer identifies predictive and prognostic biomarkers for disease progression and rationalizes breast cancer subtype-based treatment options. The expression status of hormone and growth factor receptors dictates the options for chemo-endocrine and/or pathway selective small molecule inhibitor-based treatments. Overall, these treatment options are associated with long-term systemic toxicity and acquired tumor resistance, predominantly due to the emergence of drug-resistant cancer stem cell population and due to therapy-resistant disease progression. These limitations emphasize the identification of non-toxic testable therapeutic alternatives for the efficacious targeting of breast cancer stem cells. The present review summarizes published evidence focused on i) developing cellular models for molecular subtypes of breast cancer; ii) isolating and characterizing drug-resistant cancer stem cells from the developed models; and iii) identifying mechanistic leads for potential stem cell-targeting lead compounds. Cellular models for Luminal A, human epidermal growth factor receptor-2 (HER-2) enriched and triple-negative breast cancer subtypes represented the experimental models. Prototypic chemo-endocrine therapeutic agents were used to select the drug-resistant stem cell phenotype. The vitamin A derivative, all-trans retinoic acid, and the rosemary terpenoid, carnosol, respectively representing a mechanistically distinct natural product and a potential bio-active constituent of a nutritional herb provided stem cell-selective lead compounds. The cellular models for Luminal A, HER-2-enriched and triple-negative breast cancer subtypes exhibited growth inhibitory effects in response to treatment with prototypic chemo-endocrine therapeutics, natural products and nutritional herbs. Drug-resistant phenotypes exhibited an upregulated expression of stem cell-specific cellular and molecular markers. Lead compounds induced the downregulated expression of the
\end{abstract}

Correspondence to: Dr Nitin Telang, Cancer Prevention Research Program, Palindrome Liaisons Consultants, 10 Rolling Ridge Road, Suite B, Montvale, NJ 07645-1559, USA

E-mail: ntelang3@gmail.com; entitytoo@gmail.com

Key words: drug resistance, stem cells, breast cancer models stem cell markers in drug-resistant phenotypes. These data validate an experimental approach with which to identify potential non-toxic natural products and nutritional herbs that may represent testable alternatives for the stem cell targeted therapy of breast cancer.
Contents
1. Introduction
2. Cellular models
3. Test agents
4. Mechanistic efficacy
5. Drug-resistant stem cell models
6. Stem cell-selective lead compound efficacy
7. Conclusions and future prospects

\section{Introduction}

Metastatic breast cancer represents a major cause of mortality in women in the USA. A recent report from the American Cancer Society estimated 266,120 newly diagnosed cases of breast cancer and 41,400 breast cancer-related deaths in 2019 (1). The global gene expression profiling of clinical breast cancers has provided a molecular classification based on hormone receptor and growth factor receptor expression (2). The identification of molecular subtypes dictates specific chemo-endocrine therapy and pathway selective small molecule inhibitor-based treatment options. Thus, selective estrogen receptor modulators, selective estrogen receptor degraders, aromatase inhibitors with or without CDK 4/6 inhibitors (3-5), human epidermal growth factor receptor-2 (HER-2)-targeted (6), PI3K/AKT-targeted or m-TOR-targeted (7-10) therapeutic options represent the treatment of choice. Long-term therapy is frequently associated with systemic toxicity and acquired tumor resistance due to the emergence of drug-resistant cancer stem cell populations that collectively compromise patient compliance and favor therapy-resistant cancer progression (11). These limitations emphasize the identification of non-toxic testable alternatives for the efficacious stem cell targeted treatment of breast cancer.

Naturally occurring phytochemicals and nutritional herbs are extensively used in alternative medicine and traditional Chinese medicine for general health issues, as well as for 
the palliative treatment for breast cancer. These agents have documented growth inhibitory efficacy via distinct mechanisms in cellular models of Luminal A, HER-2-enriched and triple-negative molecular subtypes of clinical breast cancer $(12,13)$. These relatively non-toxic agents may provide testable alternatives for chemo-endocrine therapy-resistant breast cancer by targeting drug-resistant cancer stem cells.

The present review summarizes experimental data on optimizing cellular models for select breast cancer subtypes, isolating and characterizing drug-resistant stem cell phenotypes and providing mechanistic leads for potential lead compounds for the stem cell targeted therapy of clinical breast cancer.

\section{Cellular models}

Human breast carcinoma-derived cell lines provide valuable cellular models for molecular subtypes $(14,15)$. Table I summarizes the status of hormone and growth factor receptor expression in cellular models for select breast cancer subtypes. The hormone receptor-positive, HER-2-negative Luminal A subtype responds to endocrine therapy comprising of selective estrogen receptor modulators, aromatase inhibitors and CDK 4/6 inhibitors. The hormone receptor-positive, HER-2-positive Luminal B subtype responds to endocrine therapy and to HER-2 targeted therapy. The hormone receptor-negative, HER-2-positive HER-2 enriched subtype responds to cytotoxic chemotherapy and HER-2 targeted therapy. The hormone receptor-negative HER-2-negative triple-negative subtype responds to cytotoxic chemotherapy and select small molecule inhibitors. Thus, the molecular classification has provided valuable leads for breast cancer subtype-selective therapeutic interventions (2-10).

\section{Test agents}

Mechanistically distinct clinically relevant therapeutic agents, natural products and select nutritional herbs represented the test agents in the cellular models for Luminal A, HER-2-enriched and triple-negative molecular subtypes of clinical breast cancer. Table II summarizes the maximum cytostatic concentrations and clinical applications of the test agents. Tamoxifen (TAM), Lapatinib (LAP) and Doxorubicin (DOX) represented the positive controls for Luminal A, HER-2-enriched and triple-negative models, respectively $(16,17)$. The maximum cytostatic concentrations of these agents, identified by dose response experiments were used to select the drug-resistant phenotype. The vitamin A derivative, all-trans retinoic acid (ATRA) and the rosemary terpenoid, carnosol (CSOL), were utilized to examine their efficacy on the cancer stem cell phenotype.

Mechanistic evidence for the growth inhibitory efficacy of relatively non-toxic natural products, including gucosinolates, polyphenols, isoflavones and terpenoids, as well as nutritional herbs suggest the potential applicability of these agents as testable alternatives for conventional chemo-endocrine therapy $(12,18-21)$.

\section{Mechanistic efficacy}

Published evidence summarized in Table III has identified susceptible mechanistic pathways and potential
Table I. Cellular models for the molecular subtypes of clinical breast cancer.

\begin{tabular}{lll}
\hline Model & Receptor status & $\begin{array}{c}\text { Molecular } \\
\text { subtype }\end{array}$ \\
\hline MCF-7 & $\mathrm{ER}^{+}, \mathrm{PR}^{+}, \mathrm{HER}^{-} 2^{-}$ & Luminal A \\
T47D & $\mathrm{ER}^{+}, \mathrm{PR}^{+}, \mathrm{HER}^{-}$ & Luminal A \\
BT474 & $\mathrm{ER}^{+}, \mathrm{PR}^{+}, \mathrm{HER}^{+}$ & Luminal B \\
MDA-MB-361 & $\mathrm{ER}^{+}, \mathrm{PR}^{+}, \mathrm{HER}-2^{+}$ & Luminal B \\
SKBr-3 & $\mathrm{ER}^{-}, \mathrm{PR}^{-}, \mathrm{HER}-2^{+}$ & HER-2-enriched \\
184-B5/HER & $\mathrm{ER}^{-}, \mathrm{PR}^{-}, \mathrm{HER}-2^{+}$ & HER-2-enriched \\
MDA-MB-231 & $\mathrm{ER}^{-}, \mathrm{PR}^{-}, \mathrm{HER}-2^{-}$ & Triple-negative \\
\hline
\end{tabular}

ER, estrogen receptor- $\alpha$; PR, progesterone receptor; HER-2, human epidermal growth factor receptor-2. [Data are summarized from previous studies $(14,15,21)]$.

molecular targets for the growth inhibitory efficacy of test agents in cellular models for breast cancer subtypes. Thus, in the Luminal A model represented by MCF-7 cells, TAM, Cornus officinalis (CO) and Epimedium grandiflorum (EG) inhibit anchorage-independent colony formation, induce $\mathrm{G}_{1}$ phase arrest and apoptosis $(12,13,18)$. In the HER-2-enriched model represented by 184-B5/HER cells, ATRA and CSOL inhibit colony formation, induce $\mathrm{G}_{2} / \mathrm{M}$ phase arrest and inhibit cyclooxygenase (COX)-2 expression (21-23). In the triple-negative model represented by MDA-MB-231 cells, the anti-proliferative effects of $\mathrm{CO}$ and DA involve the RB and Ras signaling pathways, respectively $(19,20)$. With regard to the nutritional herbs, it is conceivable that individual herbs may contain multiple bioactive agents. Thus, $\mathrm{CO}$ represents a major source for biologically active anthocyanins $(24,25)$, EG contains Icariin and icaritin (26,27), and several Chinese nutritional herbs that contain flavonoids, including DA and EG may be effective in the prevention/therapy of metastatic breast cancer $(28,29)$. These bio-active agents may in part be responsible for the growth inhibitory efficacy of the nutritional herbs.

\section{Drug-resistant stem cell models}

Drug-resistant stem cell phenotypes were selected from MCF-7, 184-B5/HER and MDA-MB-231 parental cells, based on their progressive growth in the presence of cytotoxic concentrations of TAM, LAP and DOX, respectively (30). Cellular markers, including tumor spheroid formation and the expression of CD44 have documented selectivity for cancer stem cells. In addition, nuclear transcription factors, including octamer-binding transcription factor-4 (Oct-4), Kruppel-like factor-4 (Klf-4), sex determining region Y-box-2 (SOX-2), c-Myc and NANOG exhibit stem cell selectivity, and these nuclear factors are also critical for the maintenance of induced pluripotent stem cells (31-33). The TAM-R, LAP-R and DOX-R phenotypes were characterized for their stem cell properties by examining the status of the expression of select stem cell-specific cellular and molecular markers. The stem cell-specific cellular markers included tumor spheroid formation and CD44 expression. The stem-cell specific molecular markers included the nuclear 
Table II. Test agents.

\begin{tabular}{llcl}
\hline Agent & \multicolumn{1}{c}{ Identity } & $\begin{array}{c}\text { Maximum cytostatic } \\
\text { concentration }\left(\mathrm{IC}_{90}\right)^{\mathrm{a}}\end{array}$ & Clinical application \\
\hline TAM & SERM & $1.5 \mu \mathrm{M}$ & $\begin{array}{c}\text { Anti-estrogen therapy } \\
\text { Anti-HER-2 therapy } \\
\text { LAP }\end{array}$ \\
DOX & EGFR/HER-2 inhibitor & $10 \mu \mathrm{M}$ & Chemotherapy \\
ATRA & Anthracyclin & $0.5 \mu \mathrm{M}$ & Retinoid therapy \\
CSOL & Vitamin A derivative & $3 \mu \mathrm{M}$ & Nutritional herb \\
CO & Rosemary terpenoid & $5 \mu \mathrm{M}$ & Nutritional herb \\
EG & & $0.07-0.5 \%$ & Nutritional herb \\
DA & & $0.44 \%$ & Nutritional herb \\
\hline
\end{tabular}

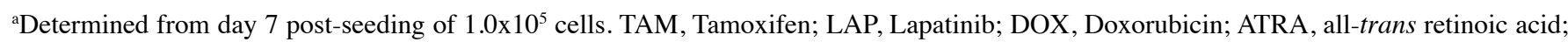
CSOL, carnosol; CO, Cornus officinalis; EG, Epimedium grandiflorum; DA, Dipsacus asperoides. [Data are summarized from previous studies $(16,17,19-22)]$.

Table III. Mechanistic efficacy of test agents in breast cancer models.

\begin{tabular}{|c|c|c|c|}
\hline Model & Clinical subtype & Agent & Molecular targets \\
\hline MCF-7 & Luminal A & TAM, CO, EG & $\begin{array}{l}\text { AIC, } \mathrm{G}_{1} \text { arrest, apoptosis, } \\
\text { BCL-2/BAX }\end{array}$ \\
\hline 184-B5/HER & HER-2 enriched & ATRA, CSOL & $\begin{array}{l}\text { AIC, RAR- } \beta, \text { COX- } 2, \\
\mathrm{G}_{2} / \mathrm{M} \text { arrest, cyclin B } 1\end{array}$ \\
\hline MDA-MB-231 & TNBC & $\begin{array}{l}\mathrm{CO} \\
\mathrm{DA}\end{array}$ & $\begin{array}{l}\mathrm{G}_{1}-\mathrm{S} \text { transition, cyclin D1, RB } \\
\mathrm{RB}, \text { cyclin D1, CDK4/6, } \\
\mathrm{RAF} / \mathrm{MEK} / \mathrm{ERK}, \mathrm{CDKI} \text { p21 }\end{array}$ \\
\hline
\end{tabular}

TAM, Tamoxifen; CO, Cornus officinalis; EG, Epimedium grandiflorum; ATRA, all-trans retinoic acid; CSOL, carnosol; DA, Dipsacus asperoides; AIC, anchorage-independent growth; BCL-2, B-cell lymphoma-2; BAX, BCL-2-associated X protein; RAR- $\beta$, retinoic acid receptor- $\beta$; COX-2, cyclooxygenase-2; RB, retinoblastoma; CDK, cyclin-dependent kinase; RAF/MEK/ERK, RAS-mediated down-stream signaling protein molecules; CDKI, cyclin-dependent kinase inhibitor. [Data are summarized from previous studies (18-23)].

Table IV. Drug-resistant stem cell models.

\begin{tabular}{|c|c|c|c|c|}
\hline \multirow[t]{2}{*}{$\begin{array}{l}\text { Resistant } \\
\text { phenotype }\end{array}$} & \multirow{2}{*}{$\begin{array}{c}\text { Drug } \\
\text { concentration } \\
\left(\mathrm{IC}_{90}\right)\end{array}$} & \multicolumn{3}{|c|}{$\begin{array}{c}\text { Stem cell marker expression } \\
\text { (relative to sensitive phenotype) }\end{array}$} \\
\hline & & $\begin{array}{l}\text { Tumor } \\
\text { spheroids }\end{array}$ & CD44 Oct-4 & NANOG \\
\hline TAM-R & TAM $1.5 \mu \mathrm{M}$ & $+1.7 \mathrm{X}$ & $+3.8 \mathrm{X}+1.8 \mathrm{X}$ & $+1.9 \mathrm{X}$ \\
\hline LAP-R & LAP $10 \mu \mathrm{M}$ & $+2.3 \mathrm{X}$ & $+4.2 \mathrm{X}+1.9 \mathrm{X}$ & $+4.4 \mathrm{X}$ \\
\hline DOX-R & $\mathrm{DOX} 0.5 \mu \mathrm{M}$ & $+2.8 \mathrm{X}$ & $+4.4 X+2.3 X$ & $+1.5 \mathrm{X}$ \\
\hline \multicolumn{5}{|c|}{$\begin{array}{l}\text { Tumor spheroid: ISD: } 100 \text { cells; spheroid count: day } 14 \text { post-seeding. } \\
\text { ISD, initial seeding density; TAM-R, Tamoxifen-resistant; LAP-R, } \\
\text { Lapatinib-resistant; DOX-R, Doxorubicin-resistant; CD44, cluster } \\
\text { of differentiation 44; Oct-4, octamer binding transcription factor-4; } \\
\text { NANOG, homeobox transcription factor, X, fold. [Data are summa- } \\
\text { rized from previous studies; for TAM-R and DOX-R }(16,17,30) \text {; Data } \\
\text { are summarized from unpublished results for LAP-R]. }\end{array}$} \\
\hline
\end{tabular}

transcription factors, Oct-4 and NANOG. The primary data for the status of these cellular and molecular markers were obtained as incidence of tumor spheroids and as log mean immunofluorescence for the expression of CD44, Oct-4 and NANOG (30). These primary data were expressed as marker modulation (\%). The data presented in Table IV are summarized as the extent of modulation in marker expression relative to the drug sensitive phenotype. These data clearly demonstrated that the three drug-resistant stem cell phenotypes exhibited a substantial increase in the expression of stem cell-specific cellular and molecular markers.

\section{Stem cell-selective lead compound efficacy}

The primary data from the experiment designed to examine the stem cell-targeted efficacy of natural products were obtained as the incidence of tumor spheroid and as log mean immuno-fluorescence $(17,21,30)$. The data presented in Table $\mathrm{V}$ summarize the marker modulation (\%) induced by the natural products, relative to the solvent treated control. These data demonstrate that in response to treatment with the vitamin A derivative, ATRA, and with the rosemary terpenoid, CSOL, the expression of select stem cell markers was substantially downregulated. In this context, it is noteworthy 
Table V.Effects of retinoid and terpenoids on LAP-R 184-B5/HER stem cells.

\begin{tabular}{lccccc}
\hline Treatment $\begin{array}{c}\text { Concentration } \\
\left(\mathrm{IC}_{90} \mu \mathrm{M}\right)\end{array}$ & $\begin{array}{c}\text { Stem cell marker expression } \\
\text { (relative to solvent control) }\end{array}$ \\
\cline { 3 - 6 } & & $\begin{array}{c}\text { Tumor } \\
\text { spheroids }\end{array}$ & CD44 & Oct-4 & NANOG \\
\hline ATRA & $3 \mu \mathrm{M}$ & $-69.1 \%$ & $-80.9 \%$ & $-81.9 \%$ & $-71.6 \%$ \\
CSOL & $5 \mu \mathrm{M}$ & $-80.3 \%$ & $-84.4 \%$ & $-69.0 \%$ & $-74.3 \%$
\end{tabular}

ATRA, all-trans retinoic acid; CSOL, carnosol; CD44, cluster of differentiation 44; Oct-4, octamer binding transcription factor; NANOG, homeobox transcription factor. (Data are summarized from unpublished results).

that these agents exhibit anti-proliferative and pro-apoptotic effects via distinct mechanisms on parental 184-B5/HER cells that represent a cellular model for the HER-2-enriched breast cancer subtype (21-23). Additionally, ATRA targets gastric cancer stem cells and inhibits patient-derived gastric carcinoma tumor growth (34).

\section{Conclusions and future prospects}

Human tissue-derived preclinical models provide valuable approaches to reduce the extrapolation for the potential clinical translation of the data. The present review summarized the application of cellular models for select molecular subtypes of clinical breast cancer that is targeted towards developing drug-resistant cancer stem cell models. Collectively, the present review has validated approaches that identify potential testable alternatives for the stem cell targeted therapy of breast cancer. Additionally, the present review provides a rational basis for future experiments on breast cancer explant models for lead compound screening (35), patient-derived tumor xenograft models for Luminal B and triple-negative breast cancer subtypes (36), and ex vivo breast cancer organoids from chemo-endocrine therapy-resistant breast cancer (37).

\section{Acknowledgements}

The author gratefully acknowledges the productive collaboration and active participation of former colleagues in the research program entitled 'Cellular models for molecular subtypes of clinical breast cancer: Mechanistic approaches for lead compound efficacy'.

\section{Funding}

This research program has been funded in the past by US National Cancer Institute (NCI) FIRST Award (grant no. CA 44741), Program Project Grant (grant no. PO1 CA 29502), NCI Contract Research Master Agreement (grant no. CN 75029-63), the Department of Defense Breast Cancer Research Program IDEA Award (grant no. DAMD-17-94-J-4208), and by the philanthropic funds to Strang Cancer Prevention Center.

\section{Availability of data and materials}

The datasets used and/or analyzed during the current study are available from the corresponding author on reasonable request.

\section{Author's contributions}

The author contributed towards study conception, experimental design and data interpretation, and prepared the manuscript for publication.

\section{Ethics approval and consent to participate}

Not applicable.

\section{Patient consent for publication}

Not applicable.

\section{Competing interests}

The author declares that there are no competing interests.

\section{References}

1. American Cancer Society-Facts and Figures: American Cancer Society Atlanta. GA, 2018

2. Sørlie T, Perou CM, Tibshirani R, Aas T, Geisler S, Johnsen H, Hastie T, Eisen MB, van de Rijn M, Jeffrey SS, et al: Gene expression patterns of breast carcinomas distinguish tumor subclasses with clinical implications. Proc Natl Acad Sci USA 98: 10869-10874, 2001

3. Musgrove EA and Sutherland RL: Biological determinants of endocrine resistance in breast cancer. Nat Rev Cancer 9: 631-643, 2009.

4. Johnston SR and Dowsett M: Aromatase inhibitors for breast cancer: Lessons from the laboratory. Nat Rev Cancer 3: 821-831, 2003.

5. Ma CX, Reinert T, Chmielewska I and Ellis MJ: Mechanisms of aromatase inhibitor resistance. Nat Rev Cancer 15: 261-275, 2015.

6. Baselga $J$ and Swain SM: Novel anticancer targets: Revisiting ERBB2 and discovering ERBB3. Nat Rev Cancer 9: 463-475, 2009.

7. Dinh P, Sotiriou C and Piccart MJ: The evolution of treatment strategies: Aiming at the target. Breast 16 (Suppl 2): S10-S16, 2007.

8. Cleator S, Heller W and Coombes RC: Triple-negative breast cancer: Therapeutic options. Lancet Oncol 8: 235-244, 2007.

9. Anders CK, Winer EP, Ford JM, Dent R, Silver DP, Sledge GW and Carey LA: Poly(ADP-Ribose) polymerase inhibition: 'Targeted' therapy for triple-negative breast cancer. Clin Cancer Res 16: 4702-4710, 2010.

10. Ibrahim YH, García-García C, Serra V, He L, Torres-Lockhart K, Prat A, Anton P, Cozar P, Guzmán M, Grueso J, et al: PI3K inhibition impairs BRCA1/2 expression and sensitizes BRCA-proficient triple-negative breast cancer to PARP inhibition. Cancer Discov 2: 1036-1047, 2012.

11. Dean M, Fojo T and Bates S: Tumour stem cells and drug resistance. Nat Rev Cancer 5: 275-284, 2005.

12. Telang $\mathbf{N}$ and Katdare M: Epithelial cell culture models for the prevention and therapy of clinical breast cancer (Review). Oncol Lett 3: 744-750, 2012.

13. Telang N, Li G, Katdare M, Sepkovic D, Bradlow L and Wong G: Inhibitory effects of Chinese nutritional herbs in isogenic breast carcinoma cells with modulated estrogen receptor function. Oncol Lett 12: 3949-3957, 2016.

14. Neve RM, Chin K, Fridlyand J, Yeh J, Baehner FL, Fevr T, Clark L, Bayani N, Coppe JP, Tong F, Speed T, et al: A collection of breast cancer cell lines for the study of functionally distinct cancer subtypes. Cell 10: 515-527, 2006. 
15. Subik K, Lee JF, Baxter L, Strzepel T, Costello D, Crowley P, Xing L, Hung MC and Bonfiglio T: Hicks DG and tangP; Expression patterns of ER, PR, HER-2, CK5/6, Ki-67 and AR by immune-histochemical analysis in breast cancer cell lines. Breast Cancer 4: 35-41, 2010.

16. Telang N: Putative cancer-initiating stem cells in cell culture models for molecular subtypes of clinical breast cancer. Oncol Lett 10: 3840-3846, 2015.

17. Telang N: Growth inhibitory efficacy of natural products in a model for triple negative molecular subtype of clinical breast cancer. Biomed Rep 7: 199-204, 2017.

18. Telang NT, Li G, Sepkovic DW, Bradlow HL and Wong GY: Anti-proliferative effects of Chinese herb Cornus officinalis in a cell culture model for estrogen receptor-positive clinical breast cancer. Mol Med Rep 5: 22-28, 2012.

19. Telang NT, Nair HB and Wong GY: Effect of Cornus officinalis (CO) on a model for triple negative breast cancer. Cancer Res 75 (Suppl): SABCS Abstract P3-09-04, 2015.

20. Telang N, Nair HB and Wong GY: Efficacy of Disacus asperoides (DA) in a model for triple negative breast cancer. Cancer Res 76 (Suppl): SABCS Abstract P4-13-04, 2016.

21. Telang N: Anti-proliferative and pro-apoptotic effects of rosemary and constituent terpenoids in a model for the HER-2-enriched molecular subtype of clinical breast cancer. Oncol Lett 16 5489-5497, 2018

22. Jinno H, Steiner MG, Nason-Burchenal K, Osborne MP and Telang NT: Preventive efficacy of receptor class selective retinoids on HER-2/neu oncogene expressing preneoplastic human mammary epithelial cells. Int J Oncol 21: 127-134, 2002.

23. Subbaramaiah K, Cole PA and Dannenberg AJ: Retinoids and carnosol suppress cycloox ygenase-2 transcription by CREB-binding protein/p300-dependent and -independent mechanisms. Cancer Res 62: 2522-2530, 2002.

24. Seeram NP,SchutzkiR,Chandra A and Nair MG: Characterization, quantification, and bioactivities of anthocyanins in Cornus species. J Agric Food Chem 50: 2519-2523, 2002.

25. Chang JS, Chiang LC, Hsu FF and Lin CC: Chemoprevention against hepatocellular carcinoma of Cornus officinalis in vitro. Am J Chin Med 32: 717-725, 2004.

26. Sun L, Chen W, Qu L, Wu J and Si J: Icaritin reverses multidrug resistance of HepG2/ADR human hepatoma cells via downregulation of MDR1 and P glycoprotein expression. Mol Med Rep 8: 1883-1887, 2013

27. Ma HR, Wang J, Chen YF, Chen H, Wang WS and Aisa HA Icariin and icaritin stimulate the proliferation of SKBr3 cells through the GPER1-mediated modulation of the EGFR-MAPK signaling pathway. Int J Mol Med 33: 1627-1634, 2014.
28. Ye L, Jia Y, Ji KE, Sanders AJ, Xue K, Ji J, Mason MD and Jiang WG: Traditional Chinese medicine in the prevention and treatment of cancer and cancer metastasis. Oncol Lett 10: 1240-1250, 2015

29. Telang NT, Li G, Katdare M, Sepkovic DW, Bradlow HL and Wong GY: The nutritional herb Epimedium grandiflorum inhibits the growth in a model for the Luminal A molecular subtype of breast cancer. Oncol Lett 13: 2477-2482, 2017.

30. Telang NT: Drug resistant breast and colon cancer stem cells: Targeted approach for stem cell therapy. Int J Mol Med 42 (Suppl 1): S6, 2018.

31. Takahashi K, Tanabe K, Ohnuki M, Narita M, Ichisaka T, Tomoda $\mathrm{K}$ and Yamanaka S: Induction of pluripotent stem cells from adult human fibroblasts by defined factors. Cell 131: 861-872, 2007.

32. Park IH, Zhao R, West JA, Yabuuchi A, Huo H, Ince TA, Lerou PH, Lensch MW and Daley GQ: Reprogramming of human somatic cells to pluripotency with defined factors. Nature 451: 141-146, 2008.

33. Yu J, Hu K, Smuga-Otto K, Tian S, Stewart R, Slukvin II and Thomson JA: Human induced pluripotent stem cells free of vector and transgene sequences. Science 324: 797-801, 2009.

34. Nguyen PH, Giraud J, Staedel C, Chambonnier L, Dubus P, Chevret E, Bœuf H, Gauthereau X, Rousseau B, Fevre M, et al: All-trans retinoic acid targets gastric cancer stem cells and inhibits patient-derived gastric carcinoma tumor growth. Oncogene 35: 5619-5628, 2016.

35. Bruna A,Rueda OM, Greenwood W,Batra AS,CallariM,Batra RN, Pogrebniak K, Sandoval J, Cassidy JW, Tufegdzic-Vidakovic A, et al: A biobank of breast cancer explantswith preserved intra-tumor heterogeneity to screen anticancer compounds. Cell 167: 260-274. e22, 2016.

36. Marangoni E, Laurent C,Coussy F,El-Botty R, Château-Joubert S, Servely JL, de Plater L, Assayag F, Dahmani A, Montaudon E, et al: Capecetabine efficacy is correlated with TYMP and RB1 expression in PDX established from triple negative breast cancers. Clin Cancer Res 24: 2605-2615, 2018.

37. Sachs N, de Ligt J, Kopper O, Gogola E, Bounova G, Weeber F, Balgobind AV, Wind K, Gracanin A, Begthel $\mathrm{H}$, et al: A living biobank of breast cancer organoids captures disease heterogeneity. Cell 172: 373-386.e10, 2018.

This work is licensed under a Creative Commons Attribution-NonCommercial-NoDerivatives 4.0 International (CC BY-NC-ND 4.0) License. 